\title{
Synthesis, Characterization and Photocatalytic Application of Different Sizes of Gold Nanoparticles on 4-Nitrophenol
}

\author{
R. Seoudi 1,2*, F. A. Al-Marhaby ${ }^{3 *}$ \\ ${ }^{1}$ Spectroscopy Department, Physics Division, NRC, Cairo, Egypt \\ ${ }^{2}$ Department of Physics, College of Applied Science, Umm Al-Qura University, Makkah, Saudi Arabia \\ ${ }^{3}$ Department of Physics, University College in Qunfudah, Umm A-Qura University, Makkah, Saudi Arabia \\ Email:"rsmawed@yahoo.com, shabeeh-alward@hotmail.com
}

Received 20 July 2016; accepted 20 September 2016; published 23 September 2016

Copyright $(2016$ by authors and Scientific Research Publishing Inc.

This work is licensed under the Creative Commons Attribution International License (CC BY).

http://creativecommons.org/licenses/by/4.0/

(c) (i) Open Access

\begin{abstract}
In this work, different sizes of gold nanoparticles were synthesized at room temperature by using trisodium citrate as a surfactant stabilizing agent and sodium borohydride as a reducing agent. Transmission Electron Microscopy (TEM) confirmed that the samples were synthesized in spherical shapes with three different particle sizes: $4 \mathrm{~nm}, 7 \mathrm{~nm}$ and $11 \mathrm{~nm}$. Ultraviolet-visible spectra measurements were used to analyze the way that surface plasmon bands were affected by the different particles sizes. The effect of sphere size on photocatalytic reduction of 4-Nitrophenol was then studied and the rate constant of the reduction was calculated to be $0.014 \mathrm{~s}^{-1}, 0.0091 \mathrm{~s}^{-1}$ and $0.003 \mathrm{~s}^{-1}$ for particles sizes of $4 \mathrm{~nm}, 7 \mathrm{~nm}$ and $11 \mathrm{~nm}$, respectively. The results obtained indicated that small particles were more active in catalytic reduction due to their high surface energy.
\end{abstract}

Keywords

Gold Nanoparticles, Surface Plasmon Band, Photocatalyst, Rate Constant

\section{Introduction}

Nanomaterials are commonly defined as materials with an average grain size less than 100 nanometres and at least one dimension in the nanometre range [1]-[3]. Nano-sized particles exist in nature and can be created from

${ }^{*}$ Corresponding authors.

How to cite this paper: Seoudi, R. and Al-Marhaby, F.A. (2016) Synthesis, Characterization and Photocatalytic Application of Different Sizes of Gold Nanoparticles on 4-Nitrophenol. World Journal of Nano Science and Engineering, 6, 120-128.

http://dx.doi.org/10.4236/wjnse.2016.63012 
a variety of elements, minerals or products [4]. These types of materials are considered to be in a unique class. Nanostructured materials have many forms and can be in zero dimension (e.g. Quantum Dots [5]), one dimension (e.g. surface films), two dimensions (e.g. strands or fibres [6]) or three dimensions (e.g. particles). The general method of synthesis can be classed as either top-down or bottom-up [7] and synthesis implementation methods can be chemical, physical or mechanical [8] [9]. Gold nanoparticles (AuNPs) were synthesized by chemical methods via the reduction of tetrachloroauric acid $\left(\mathrm{HAuCl}_{4}\right)$ with tri-sodium citrate in an aqueous solution by Verma et al. (2014) [10]. Photocatalysis increases the rate of a chemical reaction due to the participation of an additional substance called a catalyst [11]. The role of AuNPs in catalysis applications drastically changed at the end of the 1980s, when Haruta and co-workers were able to prepare small gold particles supported on oxides and discovered these were catalytically active in CO oxidation at low temperatures [12]. Lin et al. (2013) used $\mathrm{NaBH}_{4}$ as a reducing agent to prepare AuNPs and studied the effect of nanoparticle sizes in the catalytic reduction of 4-Nitrophenol [13]. They prepared their nanoparticles in a different method and obtained $1.7-8.2 \mathrm{~nm}$ AuNPs. Their results obtained that the catalytic activity increased with decreasing size, with the best performance from $3.4 \mathrm{~nm}$ AuNPs. However, they observed that smaller particles, $1.7 \mathrm{~nm}$ AuNPs, deviated from this trend. Seoudi and Said (2011) prepared AuNPs at $10 \mathrm{~nm}, 9 \mathrm{~nm}$ and $11 \mathrm{~nm}$ using sodium citrate, cetyltrimethylammonium bromide (CTAB), and chitosan as capping materials. The catalytic activities of AuNPs were studied for 4-Nitrophenol reduction by $\mathrm{NaBH}_{4}$ as a model reaction. They concluded that AuNPs catalyzed the electron transfer process between $\mathrm{BH}_{4}^{-1}$ and nitro compounds with all the capping materials used AuNPs capped by chitosan was more active for the reduction than the other two [14]. AuNPs have been more recently tested in hydrogenation reactions and it seems that they are also very promising catalysts for these types of reactions due to their high selectivity in $\mathrm{C}=\mathrm{C}$ and $\mathrm{C}=\mathrm{O}$ bond hydrogenation [15]. In this work, AuNPs of different sizes were prepared using different molar ratios of tri-sodium citrate $\left(\mathrm{Na}_{3} \mathrm{C}_{6} \mathrm{H}_{5} \mathrm{O}_{7}\right)$ as a stabilizing agent. The effect of this stabilizing agent on the particle size and plasmon bands was investigated using TEM and UV-VIS measurements. The prepared samples were used in the reduction of 4-Nitrophenol (4-NP) to 4-Aminophenol (4-AP) using $\mathrm{NaBH}_{4}$ as a model reaction to clarify the effect of particle size on reduction dependence.

\section{Experimental}

\subsection{Chemicals}

All chemicals-hydrogen tetrachloroauratetrihydrate $\left(\mathrm{HAuCl}_{4} \cdot 3 \mathrm{H}_{2} \mathrm{O}, 99.9 \%\right.$, ) molecular weight: $339.79 \mathrm{~g} / \mathrm{mol}$, tri-sodium citrate dihydrate $\left(\mathrm{HOC}(\mathrm{COONa})\left(\mathrm{CH}_{2} \mathrm{COONa}\right)_{2} \cdot 2 \mathrm{H}_{2} \mathrm{O}\right)$ molecular weight: $294.10 \mathrm{~g} / \mathrm{mol}$, sodium borohydride $\left(\mathrm{NaBH}_{4}\right)$ molecular weight: 37.83 and 4-Nitrophenol (4-NP) molecular weight: 139.11 were purchased from Sigma-Aldrich (USA) and used as received without further purification. Unless mentioned, distilled and deionized water was used as a solvent in all the preparations.

\subsection{Preparation of Colloidal AuNPs by Chemical Methods}

The molar concentration was calculated using the formula; $C=(m / V) \times(1 / M W)$, where $C$ is the molar concentration in mol/L, $\mathrm{m}$ is the $\mathrm{m}$ is the weight, MW is the molecular weight and $\mathrm{V}$ is the volume which is the method of expressing the concentration of a solute in a solution. $0.00849 \mathrm{gm}$ of $\mathrm{HAuCl}_{4} \cdot 3 \mathrm{H}_{2} \mathrm{O}$ was dissolved in $100 \mathrm{~mL}$ deionized water to prepare a stock solution of hydrogen tetrachloroauratetrihydrate with a predetermined concentration of metal salt $\left(\mathrm{HAuCl}_{4} \cdot 3 \mathrm{H}_{2} \mathrm{O} ; 2.5 \times 10^{-4} \mathrm{M}\right)$ and 0.0074 gm of tri-sodium citrate dihydratewas dissolved in $100 \mathrm{~mL}$ deionized water to prepare $\left(\mathrm{HOC}(\mathrm{COONa})\left(\mathrm{CH}_{2} \mathrm{COONa}\right)_{2} \cdot 2 \mathrm{H}_{2} \mathrm{O}, 2.5 \times 10^{-4} \mathrm{M}\right)$. Stock solution was made in a conical flask and kept in the dark to protect against light. Next, ice cold sodium borohydride $\left(\mathrm{NaBH}_{4}\right) 0.1 \mathrm{M}$ was prepared by dissolved of $0.0378 \mathrm{gm}$ in $100 \mathrm{~mL}$ deionized water as a stock solution. In a typical synthesis (S1); $3.5 \mathrm{~mL}$ of $2.5 \times 10^{-4} \mathrm{M}$ tri-sodium citrate dihydrate was mixed with $10 \mathrm{~mL}$ of $2.5 \times$ $10^{-4} \mathrm{M}$ chloroauric acid solution under magnetic stirring for $10 \mathrm{~min}$ at room temperature, then $0.3 \mathrm{~mL}$ ice cold $\mathrm{NaBH}_{4}$ was added. The color of the mixture changed to pink quickly and became deep pink due to the formation of AuNPs. The last two samples (S2 and S3) were prepared by the same procedure except that the molar ratio of tri-sodium citrate dehydrate was changed by adding 15 and $30 \mathrm{~mL}$ of $\mathrm{HOC}(\mathrm{COONa})\left(\mathrm{CH}_{2} \mathrm{COONa}\right)_{2} \cdot 2 \mathrm{H}_{2} \mathrm{O} 2.5 \times$ $10^{-4} \mathrm{M}$ to $10 \mathrm{~mL}$ of $2.5 \times 10^{-4} \mathrm{M}$ chloroauric acid.

\subsection{Characterization}

The morphology and distribution of the AuNPs samples were analysed using images from transmission electron 
microscopy (TEM). TEM (JEOL-JEM-1011), Japan was operated at an accelerating voltage of $120 \mathrm{kV}$. The samples for TEM were prepared by depositing a drop of colloidal AuNPs on a carbon-coated standard copper grid (300 meshes) and allowed to dry before the TEM measurements were taken. The UV-VIS absorption spectra of AuNP nanoparticles were measured at room temperature on a spectrophotometer (Thermo-scientific Evolution 220) in a $1 \mathrm{~cm}$ optical path quartz cuvette over wavelengths of $300-900 \mathrm{~nm}$ at a resolution of $2 \mathrm{~nm}$.

\subsection{Photo-Catalytic Reduction of 4-NP Using $\mathrm{NaBH}_{4}$ and Colloidal AuNPs}

The photo-catalytic reduction of 4-NP was performed in a quartz cuvette $4 \mathrm{~cm}$ in height with $1 \mathrm{~cm}$ path length. An aqueous solution of $0.03 \mathrm{M} \mathrm{NaBH}_{4}$ and 4-NP (2 mmol) was prepared and kept at $4^{\circ} \mathrm{C}$. The photo-catalytic reduction was studied by mixing $200 \mu \mathrm{L}(2 \mathrm{mmol})$ of 4-NP with $2 \mathrm{~mL}$ deionized water in a cuvette and then adding $1 \mathrm{~mL}$ of $0.03 \mathrm{M} \mathrm{NaBH}_{4}$ to the mixture. The UV-VIS spectra were measured at different times. The distance between the light source and the cuvette containing the mixture was kept constant in all cases while measurements were taken. The same reaction was carried out in a cuvette again and $300 \mu \mathrm{L}$ of colloidal AuNPs (S1) was added so that the UV-VIS spectra could be monitored at different times in situ using a UV-VIS spectrophotometer (Thermo-scientific Evolution 220). The last two colloidal AuNPs samples (S2 and S3) used the same volumes $(300 \mu \mathrm{L})$ of the mixture and same concentrations of 4-NP and $\mathrm{NaBH}_{4}$. The spectra of these two mixtures were measured multiple times. The reaction temperature was held constant at room temperature $\left(20^{\circ} \mathrm{C}\right)$ to reduce thermal effects on the catalytic rate. The time the reduction started and completed varied depending on the size of the nanoparticle.

\section{Results and Discussion}

Figure 1 shows the transmission electron microscopy (TEM) images of AuNPs prepared with different molar ratios of trisodium citrate. All the nanoparticles synthesized were roughly spherical in shape and morphologies were irregularly distributed in two of the samples (S1 and S3) and regularly distributed in sample S2. The diameter of the particles was measured using a millimetre scale and the number of particles within a bin of 5 mm with different average diameters was counted [16]. It was noted that the particle size decreased with decreasing concentration of tri-sodium citrate. The results agree with the previous work of Zabetakis et al. (2012) [17]. The negatively charged layer of citrate ions act as electrostatic stabilization and it is prevent the agglomeration of AuNPs. Lower level of citrate favor increased growth/agglomeration of the nanoparticles. Aggregated species can be attributed to the rapid reduction of AuIII by large excess of citrate. So that strongly reduction nature of tri-sodium citrate inducing rapid nucleation is followed by agglomeration rather than an extended particles growth phase. The average size of the Au nanoparticles was found to be $\approx 4 \mathrm{~nm}, 7 \mathrm{~nm}$ and $11 \mathrm{~nm}$ for samples S1, S2 and S3, respectively. TEM measurements of the three AuNPs samples exhibit a narrow size polydisprisity and it decrease with increasing the particle sizes due to the seeding growth process and sefl-focusing formation of AuNPs. Moreover the size polydispersity changed with the change of trisodium citrate concentrations. Figure 2 shows the UV-VIS absorption spectra of the gold nanoparticles synthesized with different particle sizes: $4 \mathrm{~nm}$ (S1), $7 \mathrm{~nm}$ (S2) and $11 \mathrm{~nm}$ (S3). From this figure we see that a sharp peak was observed at three wavelengths (512, 513 and $514 \mathrm{~nm}$ ) for the three samples (S1-S3), respectively. The band shifted to a higher wavelength with increasing size of the nanoparticle due to the quantum size effect. These bands are assigned to the surface plasmon band of the gold nanoparticles and distinguished by their red color. It can be seen that the position and width of the SRP bands dependent on the size and polydispersity that affected by the molar ration of the reactant. These bands express a collective oscillation frequency for the electrons in the conduction band. The electrons submitted to these sizes of AuNPs are much smaller than the incident wavelength of the light. In this case, the electric field induced by light $E_{o}$ is constant and the electrons submit to the electromagnetic field and propagate like a plasmon wave. Considering that the atoms' nuclei are still, the oscillation of the electrons leads to a periodic charge separation and generates oscillating dipoles whose magnitude reaches a maximum at the nanoparticles' surface. At resonance, the amplitude of the local electric field in the particle, $E_{1}$, is enhanced compared to that of the applied field $E_{o}$. The optical excitation of the SPR that described a collective oscillation of the conduction electrons of the AuNPs appears as a broad absorbance bands. This is because the coupling of incident electromagnetic radiation into a surface plasmon happened at the interface between the particle and the medium surrounding the particle. As well as, large bandwidth of the plasmon can be associated with the dephasing of the coherent electron oscillation and corresponds to the rapid loss of the coherent electron motion which 

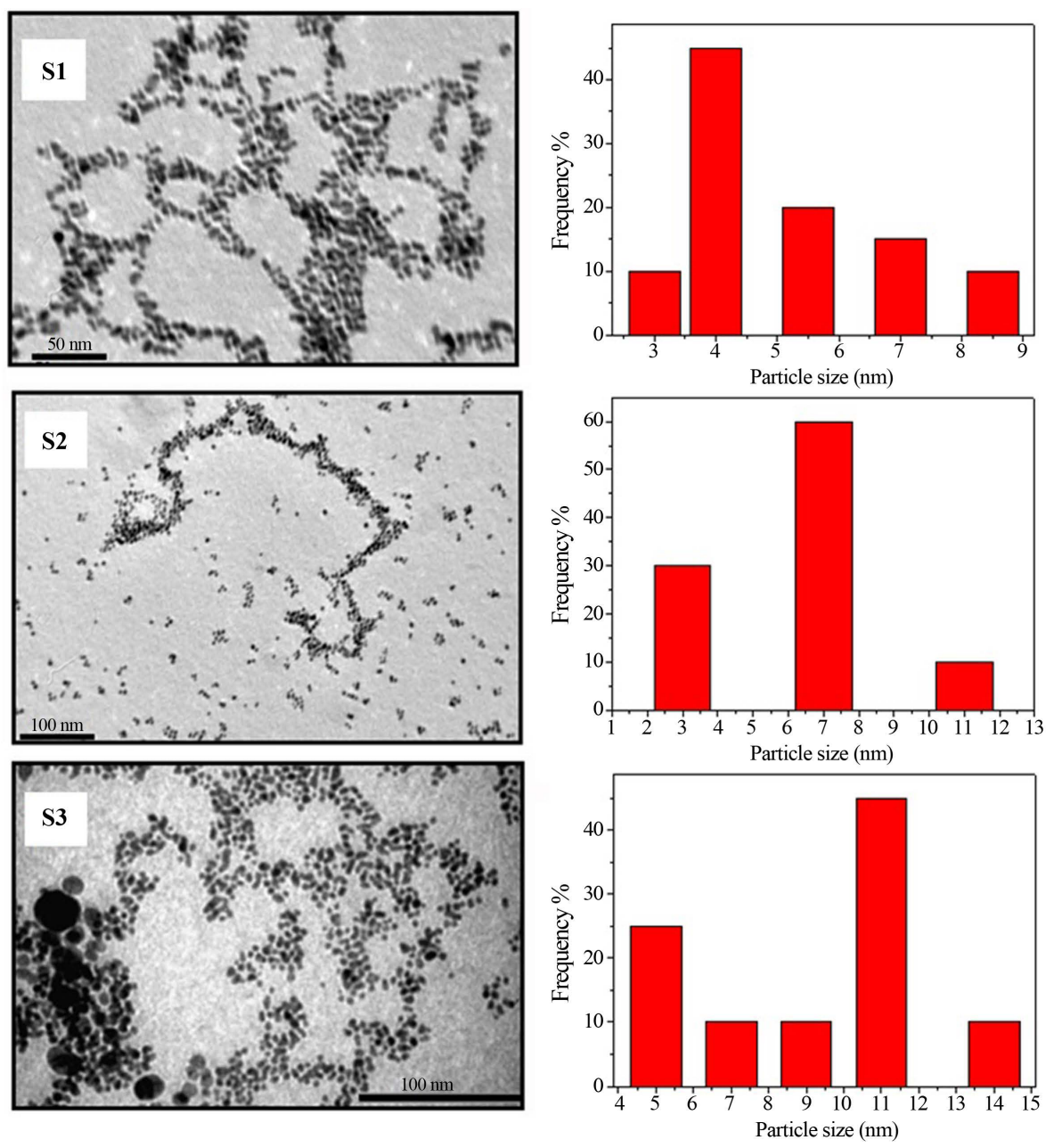

Figure 1. Transmission electron microscopy (TEM) images of AuNPs prepared at different molar ratios of chloroauric acid and trisodium citrate; sample S1 (20:7), S2 (20:20) and S3 (20:60). The average particle sizes estimated from images were 4, 7 and $11 \mathrm{~nm}$ for the samples S1, S2 and S3, respectively.

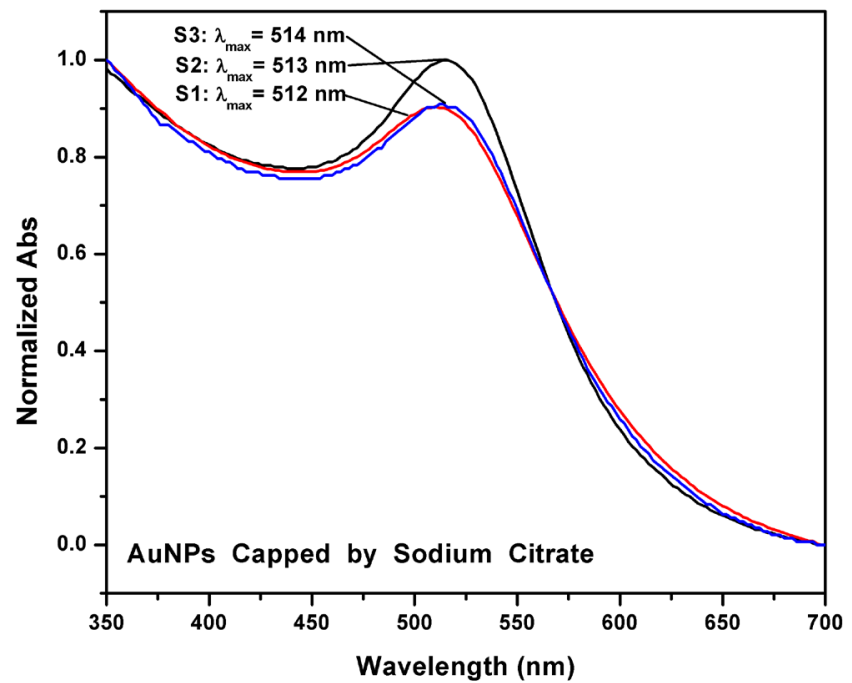

Figure 2. UV-VIS spectra of AuNPs prepared at various molar ratios of chloroauric acid and trisodium citrate; S1 (20:7), S2 (20:20) and S3 (20:60). 
strongly suggests that the main relaxation process involves electron \pm electron collisions [18]. Figure 3 illustrate the effect of nanoparticle on the surface plasmon band. Figure 4 shows the UV-VIS spectra of the 4-NP (2 mmol) with and without $\mathrm{NaBH}_{4}$. The spectrum of 4-NP without $\mathrm{NaBH}_{4}$ shows one band at $317 \mathrm{~nm}$. This band is assigned to $n-\pi^{*}$ transition owing to a lone pair of electrons (from oxygen and nitrogen atoms) in the 4-NP molecular structure. This peak was red shifted to $400 \mathrm{~nm}$ after adding $0.03 \mathrm{M} \mathrm{NaBH}_{4}$. The solution's color also changed from light yellow to yellow-green. This peak indicated the formation of 4-Nitrophenolate ions. This band showed a slight decrease with an increase in the time of reduction and become stable after 45 minutes, remaining unaltered even after a couple of days. These results indicate that the 4-NP was not reduced to 4-AP. These data agree with the previous work of polydispersity et al. [19]. The catalytic activity of AuNPs that were $4 \mathrm{~nm}$ (S1), 7 $\mathrm{nm}$ (S2) and $11 \mathrm{~nm}$ (S3) in diameter was monitored by measuring the UV-Vis spectrum of 4-NP in the 200 - 600 $\mathrm{nm}$ range at different times in the presence of $\mathrm{NaBH}_{4}$. The number of gold atoms was calculated in all samples; for $\mathrm{S} 1(4 \mathrm{~nm})$ as; radius $r=4 \mathrm{~nm}=4 \mathrm{e}^{-9} \mathrm{~m}=4 \mathrm{e}^{-7} \mathrm{~cm}$, volume $=\mathrm{V}=(4 / 3) \pi r 3=2.86 \mathrm{e}^{-19}$ cc, density $=\rho=19.3$ $\mathrm{g} / \mathrm{cc}$, mass $=v \times \rho=5.52 \mathrm{e}^{-18}$ g, No of moles $\mathrm{N}=$ Mass $/$ Atomic weight $=5.52 \mathrm{e}^{-18} / 197=2.8 \mathrm{e}^{-20}$ gram- moles, No of atoms $=\mathrm{N}$ x Avogadro's number $=2.8 \mathrm{e}^{-20}$ gram-moles $\times 6.022 \mathrm{e}^{+23}$ atoms $/$ gram-mole $=16861.6=16,862$

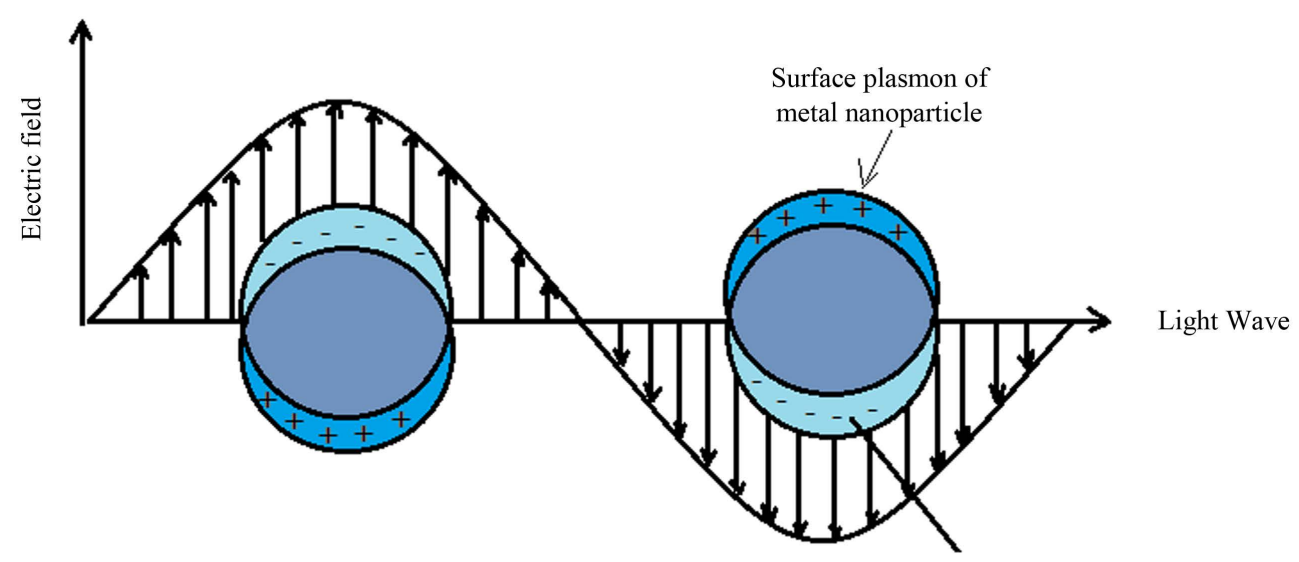

Electron cloud

Figure 3. Oscillating dipoles induced by electromagnetic radiation of gold nanoparticles.

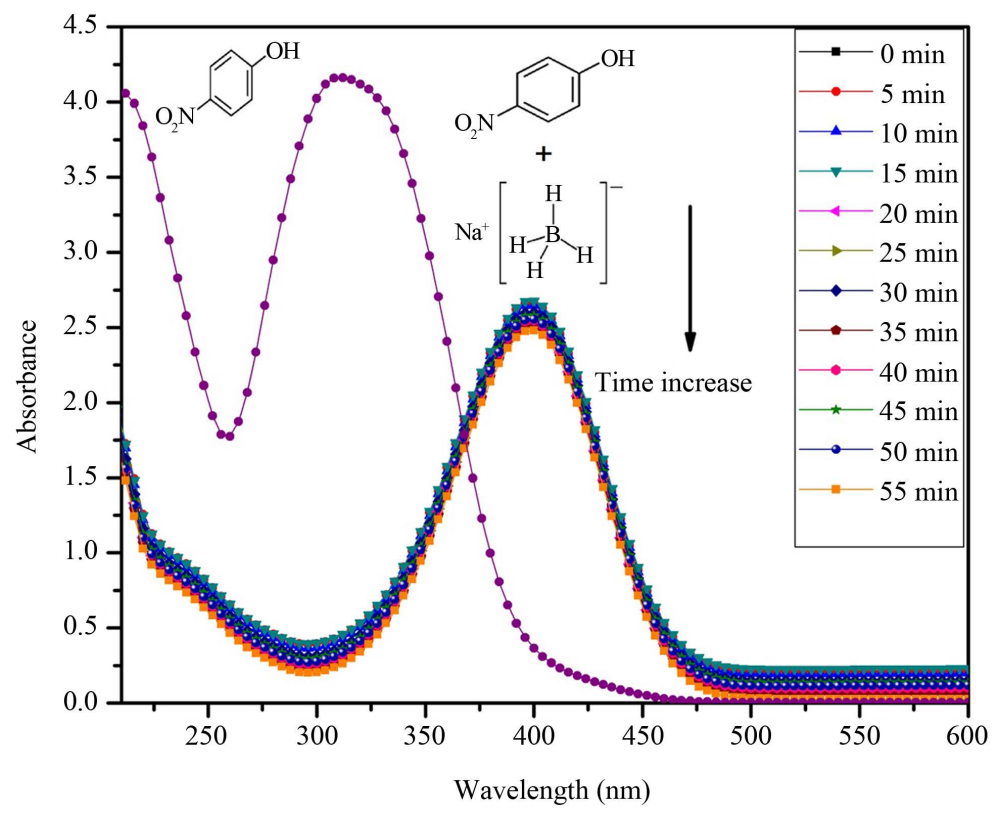

Figure 4. Measurements of the UV-VIS spectra of 4-NP over time with $\mathrm{NaBH}_{4}$ at $(400 \mathrm{~nm})$ and without sodium borohydride at $(317 \mathrm{~nm})$. 
atoms approximately. Also, the number of gold atoms was calculated for the last two samples S2 (7 nm) and S3 (11 nm) by the same method at 84,721 and 323,649, respectively. Figure 5 shows the reduction in the absorption spectra for the samples containing $200 \mu \mathrm{L}$ of 4-NP $(2 \mathrm{mmol}), 1 \mathrm{~mL}$ of $\mathrm{NaBH}_{4}(0.03 \mathrm{M})$ mixed with $2 \mathrm{~mL}$ of deionized water, and $300 \mu \mathrm{L}$ of AuNPs that were $4 \mathrm{~nm}$ (S1), $300 \mu \mathrm{L}$ of (S2) $7 \mathrm{~nm}$ and $300 \mu \mathrm{L}$ of (S3) $11 \mathrm{~nm}$ in diameter. For S1, the absorption spectrum peak at $400 \mathrm{~nm}$ decreased gradually with time. It took approximately 300 seconds for the reduction peak to be observed. This period is usually ascribed to the diffusion time needed for adsorption of 4-NP onto the surface of the gold nanoparticles. A new band then appeared at about $295 \mathrm{~nm}$. This decrease may be due to the decrease in 4-NP concentration and the new band is due to the formation of AP. The formation of this new band may be explained as follows. Firstly the $\mathrm{NaBH}_{4}$ reduces water to hydrogen as shown by the reaction:

$$
\mathrm{NaBH}_{4}+\mathrm{H}_{2} \mathrm{O} \rightarrow \mathrm{NaBO}_{2}+4 \mathrm{H}_{2}
$$

The reduction reaction is carried out by the hydrogen and involves the production of hydrogen gas that is seen in the form of bubbles. The continuous reduction in the intensity of the peak at $400 \mathrm{~nm}$ shows the consumption of 4-NP. The reaction mechanism can be reasoned by the inherent hydrogen adsorption by AuNPs. The AuNPs shuttle the hydrogen transport between $\mathrm{NaBH}_{4}$ and 4-NP. This behaviour may be explained since AuNPs adsorb

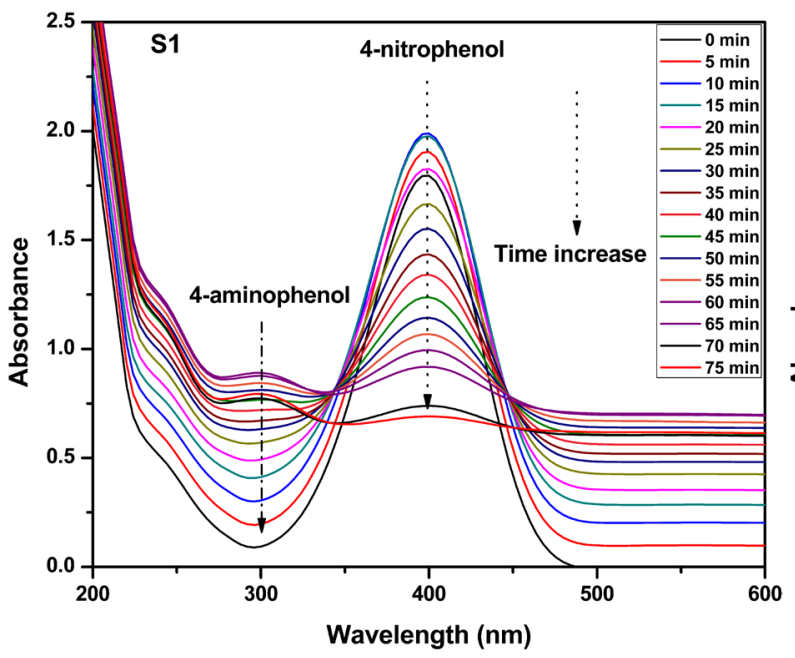

(a)

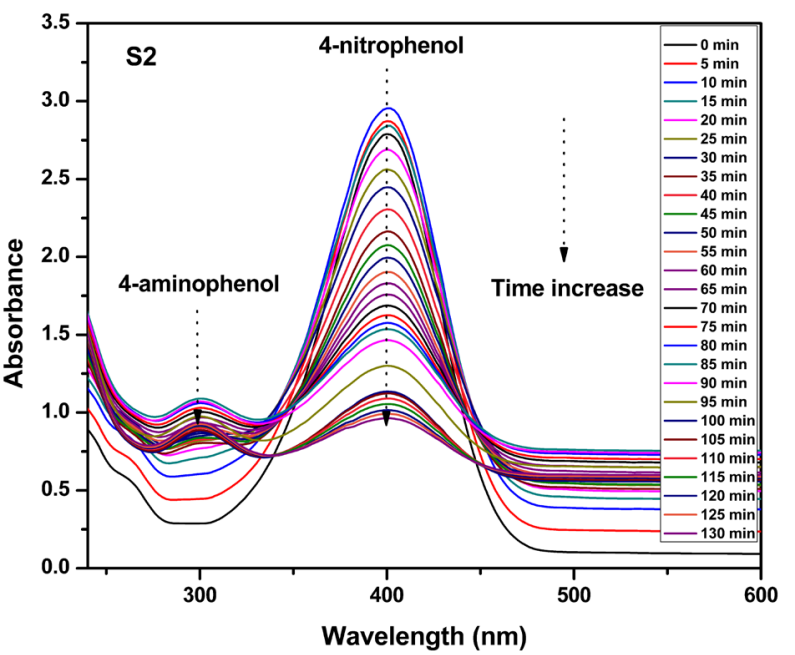

(b)

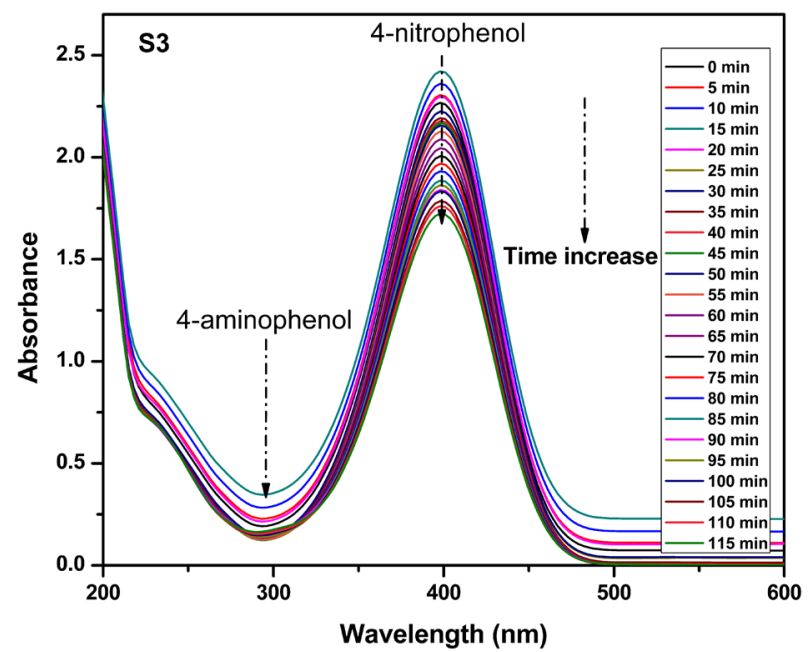

(c)

Figure 5. UV-VIS absorbance spectra for the reduction of 4-NP with $\mathrm{NaBH}_{4}$ in the presence AuNPs with particle size $4 \mathrm{~nm}$ (S1), $7 \mathrm{~nm}(\mathrm{~S} 2)$ and $11 \mathrm{~nm}(\mathrm{~S} 3)$. 
hydrogen from the $\mathrm{NaBH}_{4}$ and efficiently release it during the reduction reaction and hence AuNPs act as a hydrogen carrier in this reduction reaction. The same behaviour was seen for the reduction of 4-NP in the presence of $300 \mu \mathrm{L}$ of AuNPs in samples S2 and S3, except that the time of the reduction changed. In S2, as in S1, the absorption peak at $400 \mathrm{~nm}$ decreased with increasing time of reduction and a new band appeared at about 295 $\mathrm{nm}$, indicating the formation 4-AP. In sample S3, the absorption peak at $400 \mathrm{~nm}$ took a long time to occur and this is may have been due to the incomplete consumption of 4-NP. In addition, the intensity of the absorption band at $295 \mathrm{~nm}$ was very low. These results indicate that 4-NP did not completely transform into 4-AP in S3. It is well known that, the applications of gold nanoparticles in the catalytic application depend on the number of gold atoms on surface of nanoparticle and the sample has a larger number of atoms in the surface is more catalytic activity. Sample S1 is more active due to it has a small number of gold atom $(16,862)$ than S2 $(84,721)$ and S3 $(323,649)$ that mean it has a large number on the surface so that it has a catalytic activity than S2 and S3. The mechanisms and forms of reduction reaction for the transformation of 4-NP to 4-AP are shown in Figure 6. In this figure, two different coloured solutions are seen: one is the yellow color that distinguishes 4-NA, and the other is the reduced colourless product 4-AP. Figure 7 shows the kinetic curve of 4-NP reduction by AuNPs 4 $\mathrm{nm}$ (S1), $7 \mathrm{~nm}$ (S2) and $11 \mathrm{~nm}$ (S3) in diameter in the presence of $\mathrm{NaBH}_{4}$. The reaction rate constant was obtained by calculating the decrease in the absorption peak intensity at $400 \mathrm{~nm}$ with increasing time. In this figure, this is shown as a linear relation between $\ln \left(A / A_{o}\right)$ versus time. Since there was an excess of the reducing agent (so the concentration of sodium borohydride can be considered constant), the change in the ratio $\left(A / A_{o}\right)$ with time corresponds to a first order reaction kinetics equation. The reduction reaction can therefore be directly calculated from the linear relation between $\ln \left(A / A_{o}\right)$ and time:

$$
\ln \left(A / A_{o}\right)=-k t
$$

where $A_{o}$ is the initial absorbance of the reaction system, A is absorbance at time $t$, and $k$ is the rate constant of the chemical reduction. From this kinetic curve, the rate constant $\left(k, \mathrm{~s}^{-1}\right)$ was calculated at $0.014 \mathrm{~s}^{-1}, 0.0091 \mathrm{~s}^{-1}$
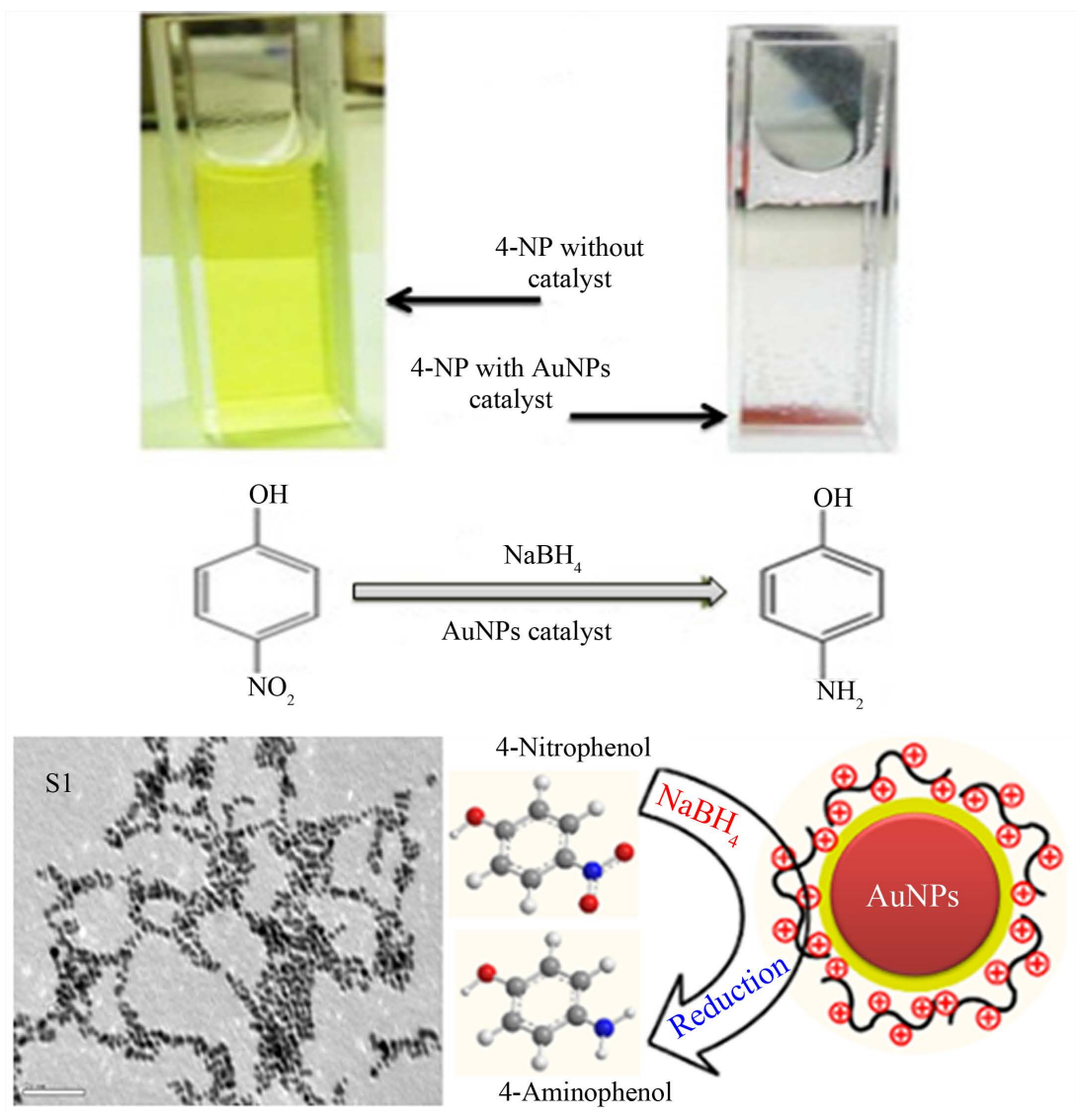

Figure 6. The mechanisms and forms of reduction reaction for 4-NP. 


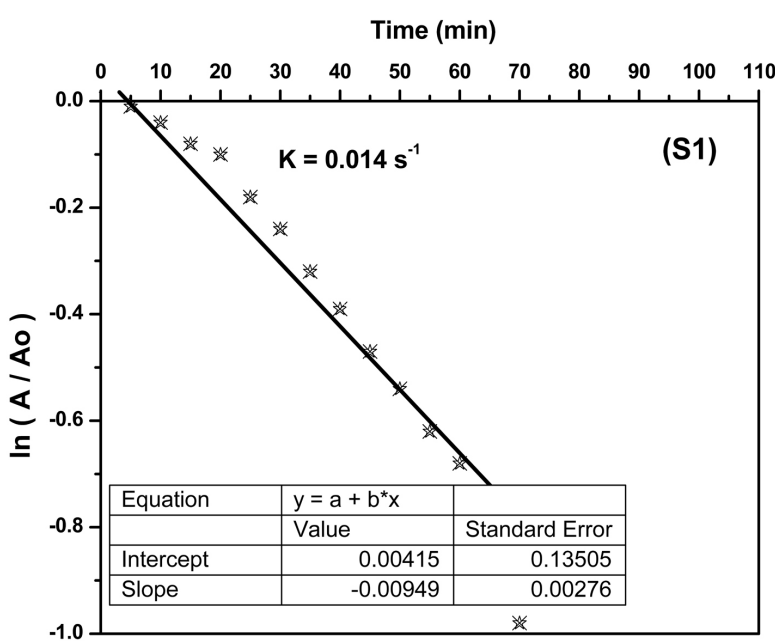

(a)

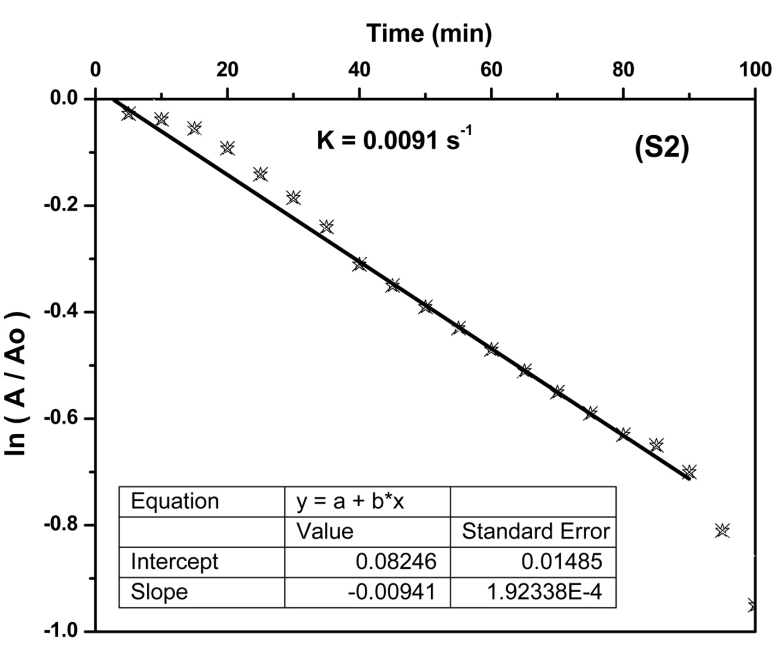

(b)

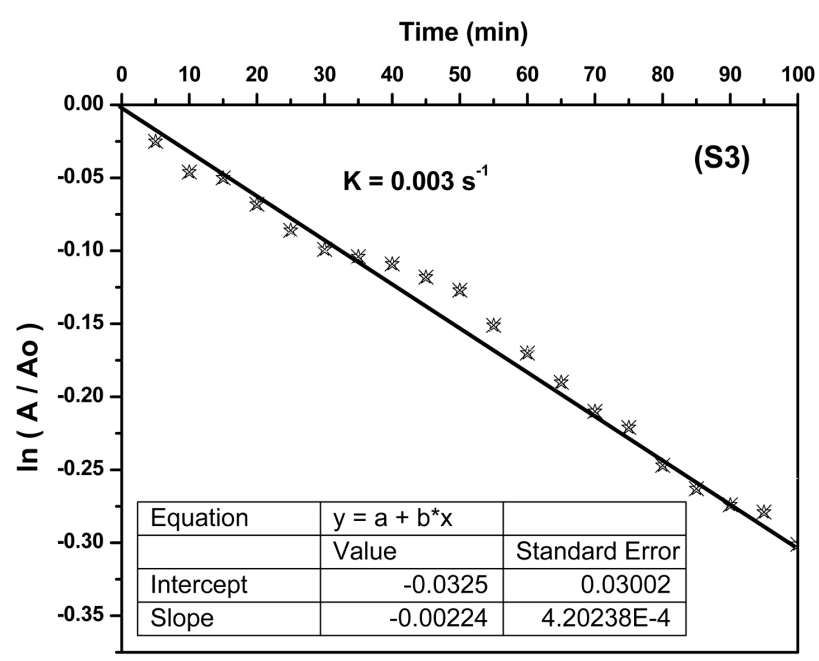

(c)

Figure 7. The kinetic curve of 4-NP reduction by AuNPs $4 \mathrm{~nm}$ in diameter in the presence of $\mathrm{NaBH}_{4}$.

and $0.003 \mathrm{~s}^{-1}$ for the AuNPs of diameter $4 \mathrm{~nm}, 7 \mathrm{~nm}$ and $11 \mathrm{~nm}$ (in S1, S2 and S3, respectively). By comparing the rate constants of 4-NP $\left(0.014 \mathrm{k}, \mathrm{s}^{-1}, 0.0091 \mathrm{k}, \mathrm{s}^{-1}\right.$ and $\left.0.003 \mathrm{k}, \mathrm{s}^{-1}\right)$ in the presence of different sizes of AuNPs ( $4 \mathrm{~nm}, 7 \mathrm{~nm}$ and $11 \mathrm{~nm}$ ), it was seen that, S1, which contained $4 \mathrm{~nm}$ AuNPs, has more catalytic activity due to the weak interaction between 4-NP and the gold nanoparticles with higher particles sizes. The reduction of 4NP by S1 and S2 can be related to the Langmuir-Hinshelwood model of heterogeneous catalysed reduction [20]. According to this model, borohydride ions are adsorbed onto the surface of the nanoparticles and give them the electrons. At the same time, molecules of 4-NP adsorbed onto the surface of AuNPs are reduced by these electrons. After reduction, the reaction product 4-AP is desorbed from the gold surface.

\section{Conclusion}

In this study, we prepared AuNPs of different sizes by a simple chemical method. The results of UV-VIS measurements showed that the surface plasmon resonance bands depended on the particle size. The prepared samples were used to reduce 4-NP, confirming that smaller nanoparticles were more active in the reduction process. The rate constant of chemical reduction was calculated for each sample and this decreased with increasing particle size. The catalytic activity of the nanoparticles can be affected and increased directly by increasing the ratio of the number of atom on the surface to volume. This ratio was increased with decreasing the particle size, so the small AuNPs size was more active in the reduction process. 


\section{References}

[1] Seoudi, R., Allehyani, H.A., Said, D.A., Lashin, A.R. and Abouelsayed, A. (2015) Preparation, Characterization, and Size Control of Chemically Synthesized CdS Nanoparticles Capped with Poly(ethylene glycol). Journal of Electronic Materials, 44, 3367-3374.http://dx.doi.org/10.1007/s11664-015-3838-X

[2] Nabok, A. (2005) Organic and Inorganic Nanostructures. Artech House, London.

[3] Allehyani, S.H.A., Seoudi, R., Said, D.A., Lashin, A.R. and Abouelsayed, A. (2015) Synthesis, Characterization, and Size Control of Zinc Sulfide Nanoparticles Capped by Poly(ethylene glycol). Journal of Electronic Materials, 44, 4227-4235.http://dx.doi.org/10.1007/s11664-015-3974-3

[4] Beaux, M.F., McIlroy, D.N. and Gustin, K.E. (2008) Utilization of Solid Nanomaterials for drug DELIVERY. Expert Opinion on Drug Delivery, 5, 725-735. http://dx.doi.org/10.1517/17425247.5.7.725

[5] Drbohlavova, J., Adam, V., Kizek, R. and Hubalek, J. (2009) Quantum Dots-Characterization, Preparation and Usage in Biological Systems. International Journal of Molecular Sciences, 10, 656-673. http://dx.doi.org/10.3390/ijms10020656

[6] Shao, Y.L., Xu, S.P., Zheng, X.L., Wang, Y. and Xu, W.Q. (2010) Optical Fiber LSPR Biosensor Prepared by Gold Nanoparticle Assembly on Polyelectrolyte Multilayer. Sensors, 10, 3585-3596. http://dx.doi.org/10.3390/s100403585

[7] Kung, H.J., Kung, L. andGardiner, A. (2012) Comparing Top-Down with Bottom-Up Approaches: Teaching Data Modeling. EDSIG Information Systems Educators. Proceedings of the Information Systems Educators Conference, New Orleans, Vol. 29, No. 1910.

[8] Singh, M., Manikandan, S. and Kumaraguru, A.K. (2011) Nanoparticles: A New Technology with Wide Applications. Research Journal of Nanoscience and Nanotechnology, 1, 1-11.

[9] Rajput, N. (2015) Methods of Preparation of Nanoparticles-A Review. International Journal of Advances in Engineering and Technology, 7, 1806-1811.

[10] Nath, V.P., Singh, H. and Chavan, R.M. (2014) Gold Nanoparticle: Synthesis and Characterization. Veterinary World, 7, 2231.

[11] Ravelli, D., Protti, S. and Albini, A. (2015) Energy and Molecules from Photochemical/Photocatalytic Reactions. An Overview. Molecules, 20, 1527-1542. http://dx.doi.org/10.3390/molecules20011527

[12] Lazar, M., Ducu, C., Almasan, V., Aldea, N., Barz, B., Marginean, P., Sutan, C. and Malinovschi, V. (2006) Nanostructured Gold Supported Catalysts: Relation between Structure and Hydrogen Catalytic Activity. Romanian Journal of Physics, 51, 299.

[13] Lin, C., Tao, K., Hua, D.Y., Ma, Z. and Zhou, S.H. (2013) Size Effect of Gold Nanoparticles in Catalytic Reduction of p-Nitrophenol with $\mathrm{NaBH}_{4}$. Molecules, 18, 12609-12620. http://dx.doi.org/10.3390/molecules181012609

[14] Seoudi, R. and Said, D.A. (2011) Studies on the Effect of the Capping Materials on theSpherical Gold Nanoparticles Catalytic Activity. World Journal of Nano Science and Engineering (WJNSE), 1, 51-61. http://dx.doi.org/10.4236/wjnse.2011.12008

[15] Zanella, R., Giorgio, S., Shin, C.H., Henry, C.R. and Louis, C. (2004) Characterization and Reactivity in CO Oxidation of Gold Nanoparticles Supported on $\mathrm{TiO}_{2}$ Prepared by Deposition-Precipitation with $\mathrm{NaOH}$ and Urea. Journal of Catalysis, 222, 357-367. http://dx.doi.org/10.1016/j.jcat.2003.11.005

[16] Dwivedi, D.K. and Dubey, M. (2009) Synthesis, Characterization and Electrical Properties of ZnTe Nanoparticles. Journal of Ovonic Research, 5, 35-41.

[17] Zabetakis, K., Ghann, W.E., Kumar, S. and Daniel, M.C. (2012) Effect of High Gold Salt Concentrations on the Size and Polydispersity of Gold Nanoparticles Prepared by an Extended Turkevich-Frens Method. Gold Bulletin, 45, 203211. http://dx.doi.org/10.1007/s13404-012-0069-2

[18] Huang, X. and El-Sayed, M.A. (2010) Gold Nanoparticles: Optical Properties and Implementations in Cancer Diagnosis and Photothermal Therapy. Journal of Advanced Research, 1, 13-28. http://dx.doi.org/10.1016/j.jare.2010.02.002

[19] Rashid, M., Bhattacharjee, R., Kotal, A. and Mandal, T. (2006) Synthesis of Spongy Gold Nanocrystals with Pronounced Catalytic Activities. Langmuir, 22, 7141-7143. http://dx.doi.org/10.1021/la060939j

[20] Khalavka, Y., Becker, J. and Soennichsen, C. (2009) Synthesis of Rod-Shaped Gold Nanorattles with Improved Plasmon Sensitivity and Catalytic Activity. Journal of the American Chemical Society, 131, 1871-1875. http://dx.doi.org/10.1021/ja806766w 


\section{Submit or recommend next manuscript to SCIRP and we will provide best service for you:}

Accepting pre-submission inquiries through Email, Facebook, LinkedIn, Twitter, etc.

A wide selection of journals (inclusive of 9 subjects, more than 200 journals)

Providing 24-hour high-quality service

User-friendly online submission system

Fair and swift peer-review system

Efficient typesetting and proofreading procedure

Display of the result of downloads and visits, as well as the number of cited articles

Maximum dissemination of your research work

Submit your manuscript at: http://papersubmission.scirp.org/

Or contactwjnse@scirp.org 